\title{
Fluoroscopic and gait analyses for the assessment of the functional performance of an original total ankle replacement
}

\author{
Francesco Cenni ${ }^{1}$, Sandro Giannini ${ }^{1,2}$, Claudio Belvedere ${ }^{1}$, Matteo Romagnoli ${ }^{2}$, Lisa Berti ${ }^{1}$, Maddalena Pieri ${ }^{1}$, \\ Alberto Leardini ${ }^{1 *}$
}

From 3rd Congress of the International Foot and Ankle Biomechanics Community

Sydney, Australia. 11-13 April 2012

\section{Background}

An original total ankle replacement design was developed with the aim of establishing compatibility between the prosthetic articulating surfaces and the retained ligaments. This was achieved with a special shape of a conforming meniscal bearing, free to move forwards/ backwards on both metal components during dorsi/ plantar flexion. Careful kinematics analyses were carried out in patients after this replacement to assess the functional performance during activity of daily living. A thorough assessment shall include standard gait analysis (GA) and the more accurate motion tracking of the components by 3D fluoroscopic analysis (FA).

\section{Materials and methods}

Eleven patients implanted with the BOX Ankle (Finsbury Orthopaedics, Leatherhead-Surrey, UK) were analyzed at 12 months after surgery. GA was performed during stair-climbing/descending using a 8-cameras motion system (Vicon Motion Systems, Oxford, UK), electromyography (ZeroWire, Aurion, Milan, Italy), and an established protocol for lower limb joint kinematics and kinetics [1]. For the same patients and motor tasks, FA was performed on the same day using a standard fluoroscope (CAT Medical System, Italy) at $10 \mathrm{~Hz}$ and an established technique [2], which works out motion of the three components in the three anatomical planes.

\section{Results}

Nearly physiological joint kinematic patterns were observed in both legs (Table 1). A statistically significant difference between the operated and controlateral sides were found only in the hip and ankle range of flexion, and in dorsi/plantar flexion at foot strike $(\mathrm{p}<0.05)$. From FA, over all patients, 1.2 and $3.4 \mathrm{~mm}$ of antero-posterior meniscal-to-tibial translation were coupled with $5.2^{\circ}$ and

Table 1 Gait analysis results

\begin{tabular}{|c|c|c|c|c|c|}
\hline & \multirow[t]{2}{*}{ Unit } & \multicolumn{2}{|c|}{ Stair climbing } & \multicolumn{2}{|c|}{ Stair descending } \\
\hline & & Operated side & Controlateral side & Operated side & Controlateral side \\
\hline Hip range of flex- extension & {$[\mathrm{Deg}]$} & $59.2 \pm 4.1$ & $46.8 \pm 6.5$ & $24.1 \pm 5.5$ & $16.3 \pm 4.1$ \\
\hline Max hip flexion moment & {$\left[\% \mathrm{BW}^{*} \mathrm{~h}\right]$} & $7.5 \pm 1.2$ & $6.3 \pm 1.1$ & $3.2 \pm 1.2$ & $5.9 \pm 6.7$ \\
\hline Knee range of flexion & [Deg] & $56.4 \pm 6.4$ & $56.5 \pm 6.7$ & $79.6 \pm 5.7$ & $76.4 \pm 5.0$ \\
\hline Max knee flexion moment & {$\left[\% \mathrm{BW}^{*} \mathrm{~h}\right]$} & $1.9 \pm 1.2$ & $5.1 \pm 2.6$ & $5.9 \pm 1.6$ & $7.7 \pm 1.6$ \\
\hline Ankle range of flexion & {$[\mathrm{Deg}]$} & $16.8 \pm 9.5$ & $38.8 \pm 9.8$ & $17.8 \pm 6.7$ & $55.5 \pm 7.5$ \\
\hline Ankle dorsi/plantar flexion at foot strike & {$[\mathrm{Deg}]$} & $5.9 \pm 4.3$ & $10.9 \pm 6.6$ & $-9.1 \pm 5.4$ & $-27.0 \pm 6.8$ \\
\hline Max ankle dorsi-flexion moment & {$\left[\% \mathrm{BW}^{*} \mathrm{~h}\right]$} & $6.8 \pm 1.2$ & $7.6 \pm 1.3$ & $6.6 \pm 1.4$ & $7.8 \pm 1.5$ \\
\hline
\end{tabular}

${ }^{1}$ Movement Analysis Laboratory, Istituto Ortopedico Rizzoli, 40136 Bologna,

Italy

Full list of author information is available at the end of the article

C 2012 Cenni et al; licensee BioMed Central Ltd. This is an Open Access article distributed under the terms of the Creative Commons Attribution License (http://creativecommons.org/licenses/by/2.0), which permits unrestricted use, distribution, and reproduction in any medium, provided the original work is properly cited. 
$8.2^{\circ}$ flexion between the two metal components, respectively during stair climbing and descending. At the replaced joint, a significant correlation was found between meniscal-motion from FA and both range of flexion and flexion at foot-strike from GA.

\section{Conclusions}

Nearly normal kinematics and kinetics at the main joints were observed also at the replaced leg. In addition, nearly natural function was restored at the replaced ankle, with large coupled motion in the three anatomical planes. The meniscal-motion was coupled with ankle flexion, supporting the main claims of the designers.

\section{Author details}

'Movement Analysis Laboratory, Istituto Ortopedico Rizzoli, 40136 Bologna, Italy. ${ }^{2}$ Department of Orthopedic Surgery, Istituto Ortopedico Rizzoli , 40136 Bologna, Italy.

Published: 10 April 2012

\section{References}

1. Leardini A, et al: A new anatomically based protocol for gait analysis in children. Gait Posture 2007, 26:560-71.

2. Catani $F$, et al: In- vivo kinematics and kinetics of a bi-cruciate substituting total knee arthroplasty: a combined fluoroscopic and gait analysis study. J Orthop Res 2009, 27:1569-75.

\section{Submit your next manuscript to BioMed Central} and take full advantage of:

- Convenient online submission

- Thorough peer review

- No space constraints or color figure charges

- Immediate publication on acceptance

- Inclusion in PubMed, CAS, Scopus and Google Scholar

- Research which is freely available for redistribution

Submit your manuscript a www.biomedcentral.com/submit 